\title{
Muscle atrophy in chronic obstructive pulmonary disease: molecular basis and potential therapeutic targets
}

\author{
Esther Barreiro $^{1,2}$, Ariel Jaitovich ${ }^{3,4}$ \\ ${ }^{1}$ Respiratory Medicine Department-Muscle Wasting and Cachexia in Chronic Respiratory Diseases and Lung Cancer Research Group, Institute of \\ Medical Research of Hospital del Mar (IMIM)-Hospital del Mar, Parc de Salut Mar, Barcelona Biomedical Research Park (PRBB), Barcelona, Spain; \\ ${ }^{2}$ Centro de Investigación en Red de Enfermedades Respiratorias (CIBERES), Instituto de Salud Carlos III (ISCIII), Barcelona, Spain; ${ }^{3}$ Division of \\ Pulmonary and Critical Care Medicine, ${ }^{4}$ Department of Molecular and Cellular Physiology, Albany Medical College, Albany, NY, USA \\ Contributions: (I) Conception and design: E Barreiro; (II) Administrative support: None; (III) Provision of study materials or patients: None; (IV) \\ Collection and assembly of data: None; (V) Data analysis and interpretation: None; (VI) Manuscript writing: All authors; (VII) Final approval of \\ manuscript: All authors. \\ Correspondence to: Dr. Esther Barreiro. Pulmonology Department-URMAR, IMIM-Hospital del Mar, PRBB, C/Dr. Aiguader, 88, Barcelona, E-08003 \\ Spain. Email: ebarreiro@imim.es.
}

\begin{abstract}
Patients with chronic obstructive pulmonary disease (COPD) experience several systemic manifestations such skeletal muscle dysfunction with and without muscle mass loss. Moreover, frequent comorbidities such as nutritional abnormalities, heart failure, and pulmonary hypertension, which are frequently associated with COPD may further contribute to skeletal muscle mass loss and dysfunction. Muscle dysfunction impairs the patients' exercise capacity and quality of life as daily life activities may be hampered by this problem. Importantly, impaired muscle function and mass loss have been shown to impact negatively on the patients' prognosis and survival in several studies. Thus, this is a major clinical problem that deserves special attention in clinical settings. During the course of exacerbations muscle mass loss takes place, hence aggravating muscle status and performance even after hospital discharge, especially in the frequently exacerbator patients. Several factors and biological mechanisms are involved in the etiology of COPD muscle dysfunction. The biological mechanisms identified so far offer a niche for therapeutic interventions in the patients. In the current review, a general overview of the most relevant etiologic factors and their target biological mechanisms through which muscle mass loss and dysfunction take place in both the respiratory and lower limb muscles in COPD patients is provided. We conclude that more clinical research is still needed targeted to test several therapeutic interventions. Given its prognostic value, the assessment of skeletal muscle dysfunction should be included in the routine evaluation of patients with chronic respiratory disorders and in critical care settings.
\end{abstract}

Keywords: Chronic obstructive pulmonary disease (COPD); muscle dysfunction; muscle atrophy; multifactorial etiology; biological mechanisms and potential therapeutic targets

Submitted Apr 18, 2018. Accepted for publication Apr 24, 2018.

doi: $10.21037 /$ jtd.2018.04.168

View this article at: http://dx.doi.org/10.21037/jtd.2018.04.168

\section{Introduction}

Chronic obstructive pulmonary disease (COPD) will become a leading cause of death worldwide over the next few years (1-4). Impairment of the patients' exercise capacity and quality of life have been both attributed to muscle dysfunction, defined as the loss of either strength or endurance properties of muscles (Figure 1) (5). Muscle dysfunction is one of the most relevant systemic manifestations of patients with COPD. Muscle mass loss or atrophy, especially in the lower limbs, is usually associated 


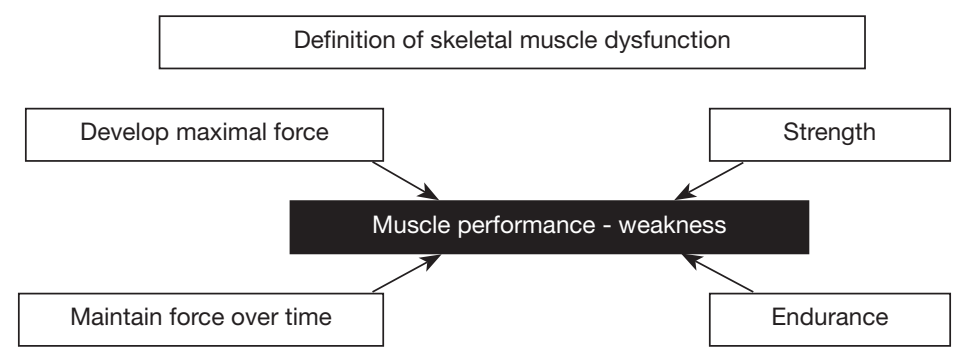

Figure 1 Schematic representation on how the two main properties of skeletal muscle contraction (strength and endurance) determine muscle performance or weakness when a significant reduction in muscle force generation (the most commonly studied parameter in COPD patients) occurs.

with impaired function of those muscles in COPD patients. Moreover, other comorbidities, which are frequent in patients with COPD, may further contribute to the loss of muscle mass and function seen in these patients. For instance, reduced physical activity, malnutrition, chronic heart failure, pulmonary hypertension may further deteriorate muscle function and mass in COPD patients $(5,6)$. Despite that COPD skeletal muscle dysfunction may affect both ventilatory and limb muscles, the latter are usually more severely affected. Interestingly, survival and COPD mortality are negatively influenced by both dysfunction of the lower limb muscles and impaired muscle mass as measured by mid-thigh cross-sectional area (5,7-9). Additionally, COPD exacerbations also rapidly induce loss of muscle mass and function through the activation of several biological pathways and systems. The risk of hypercapnic respiratory failure and exercise limitation are also very prominent features in COPD patients during acute exacerbations, which may lead to increased risk of death in these patients (10).

Whether muscle dysfunction and mass loss occur in other respiratory conditions has not been sufficiently elucidated compared to literature published in the field of COPD. Therefore, this should be a matter for future research. Nonetheless, COPD muscle dysfunction has drawn most of the investigators' attention probably as a consequence of the high prevalence of this condition as well as the socioeconomic burden of the costs related to the patients' management and treatment in the last two decades. In the current review, we offer an overview of the most relevant biological mechanisms that underlie muscle dysfunction and wasting in patients with COPD. Those biological mechanisms may offer a niche for the design of specific therapeutic targets that may alleviate muscle dysfunction and loss in patients with COPD. It should be mentioned that muscle dysfunction of the lower limbs and that of the respiratory muscles are reviewed independently in the article.

\section{Epidemics of skeletal muscle dysfunction in COPD}

In general, muscles of the lower limbs in COPD patients exhibit greater susceptibility to fatigue than age-matched healthy subjects (11-15). Strength and endurance properties are impaired in the lower limb muscles of patients with COPD (Figure 1) (16-19). Although strength is not the most sensitive surrogate to evaluate muscle function in the patients, for practical reasons it is commonly used in clinical settings.

Poor muscle function and wasting are common systemic manifestations in COPD patients. Indeed, mid-thigh crosssectional area and quadriceps weakness (defined as a decline in the ability to generate force), respectively, strongly influence exercise capacity and quality of life (20-22). Additionally, muscle weakness and atrophy lead to an increase in the use of health care resources (23), and are predictors of mortality in patients with COPD (7-9).

Quadriceps muscle dysfunction occurred in approximately one third of the COPD patients, even at early stages of their disease as demonstrated in a multicenter European-based study (24). The proportion of patients with muscle weakness was similar in the different participating countries regardless of the patients' airway obstruction (24). The prevalence of muscle weakness among the patients did not significantly correlate with disease severity as measured by Global Initiative for COPD (GOLD) stages (24). Nonetheless, the prevalence of COPD muscle weakness was associated with BODE (body mass index, airflow obstruction, dyspnea, exercise capacity) and dyspnea scores (24). In another study, quadriceps 
strength and rectus femoris cross-sectional area were also significantly reduced in a cohort of 161 COPD patients that were evenly distributed from GOLD stage I to stage IV compared to a population of age-matched healthy controls (8). Furthermore, the decrease in endurance of lower limb muscles in COPD patients with normal physical activity and mild-to-moderate disease did not correlate with airway obstruction or quadriceps muscle weakness as demonstrated in another investigation (13). The study also concluded that lower limb muscle endurance was reduced in COPD patients even in those with a mild disease and that such a decrease may antecede strength impairment of the same muscles in COPD (13). Collectively, the reported findings suggest that impairments in muscle function (strength and/or endurance) are independent of the airway obstruction or lung function status in these patients. Therefore, skeletal muscle function should be evaluated in all patients with COPD irrespective of the severity of the lung disease.

In COPD, despite that the ventilatory muscles undergo a positive adaptation (training-like effect) that renders them more fatigue-resistant $(19,25,26)$, both maximal inspiratory and expiratory pressures (strength); and endurance of these muscles were consistently reduced in different studies (19,25-28). Ventilatory muscle dysfunction imposes constraints to the patients that may worsen the underlying chronic respiratory failure frequently present in COPD patients, especially in advanced stages. Furthermore, ventilatory muscle dysfunction associates with increased risk of hospital readmissions (29). On the other hand, acute exacerbations represent a major systemic contributor that equally affects both limb and respiratory muscles in patients with COPD $(10,30)$. Specifically, in the ventilatory muscles, the need of these muscles to overcome the inspiratory loads imposed by the increased ventilatory demands resulting from the acute exacerbation may even further impair respiratory muscle strength.

\section{Multifactorial etiology of muscle dysfunction and atrophy in COPD: factors and biological mechanisms}

Several factors and biological mechanisms have been shown to participate in the multifactorial etiology of respiratory and limb muscle dysfunction in COPD. Cigarette smoking, hypoxia, hypercapnia and acidosis, various metabolic alterations, malnutrition, genetics, systemic inflammation, aging, comorbidities, concomitant treatments, exacerbations, and inactivity are counted among the most relevant etiologic factors that contribute to muscle dysfunction in COPD patients through the action of several biological mechanisms. The contribution of several factors and biological mechanisms has been thoroughly discussed in previously published reviews $(5,16-19,25)$. The most relevant biological and biochemical processes that have been shown to mediate muscle dysfunction and wasting in COPD are the following: structural abnormalities, muscle remodeling, oxidative stress and muscle wasting, epigenetic regulation of muscle mass and function, autophagy, metabolic derangements, and endoplasmic reticulum stress (5,16-19,25). Interestingly, the biological mechanisms involved in the pathophysiology of muscle dysfunction have been predominantly studied in the vastus lateralis of the quadriceps as well as in the diaphragm of patients with COPD. An overview of the most relevant etiological factors and mechanisms in both muscle types is given below.

\section{Quadriceps muscle dysfunction}

Cigarette smoking, genetics, hypoxia, hypercapnia and acidosis, metabolic derangements including vitamin $\mathrm{D}$ and testosterone deficiencies, drugs (systemic corticosteroids), other comorbidities, exacerbations, systemic inflammation, nutritional abnormalities, reduced physical activity, and aging are all etiologic factors that contribute to muscle dysfunction of the lower limbs in COPD $(5,16-19)$ (Figure 2). Nevertheless, the predominance of physical inactivity (8), nutritional abnormalities $(6,16)$, repeated exacerbations (10,30-32), and systemic corticosteroids (33) should be underscored above the other factors as the main contributors to muscle function and mass impairment, especially in advanced COPD.

As shown in Figure 3, several molecular and cellular events take place in the lower extremity muscles, which mediate the effects of the different etiologic factors in the patients, leading to modifications in the muscle phenotype and function. A fiber-type switch towards a less fatigueresistant (phenotype from slow-twitch to fast-twitch fibers) is a major feature in the vastus lateralis of patients with advanced COPD (34-37). Furthermore, fast-twitch fibers are also of smaller size in patients with advanced COPD and poor muscle mass (34-36), thus contributing to muscle weakness. Additionally, factors such as aging (38), malnutrition (39), and systemic corticosteroid treatment (40) may worsen the fast-twitch fiber atrophy observed in COPD. Besides, a reduction in the capillary numbers 


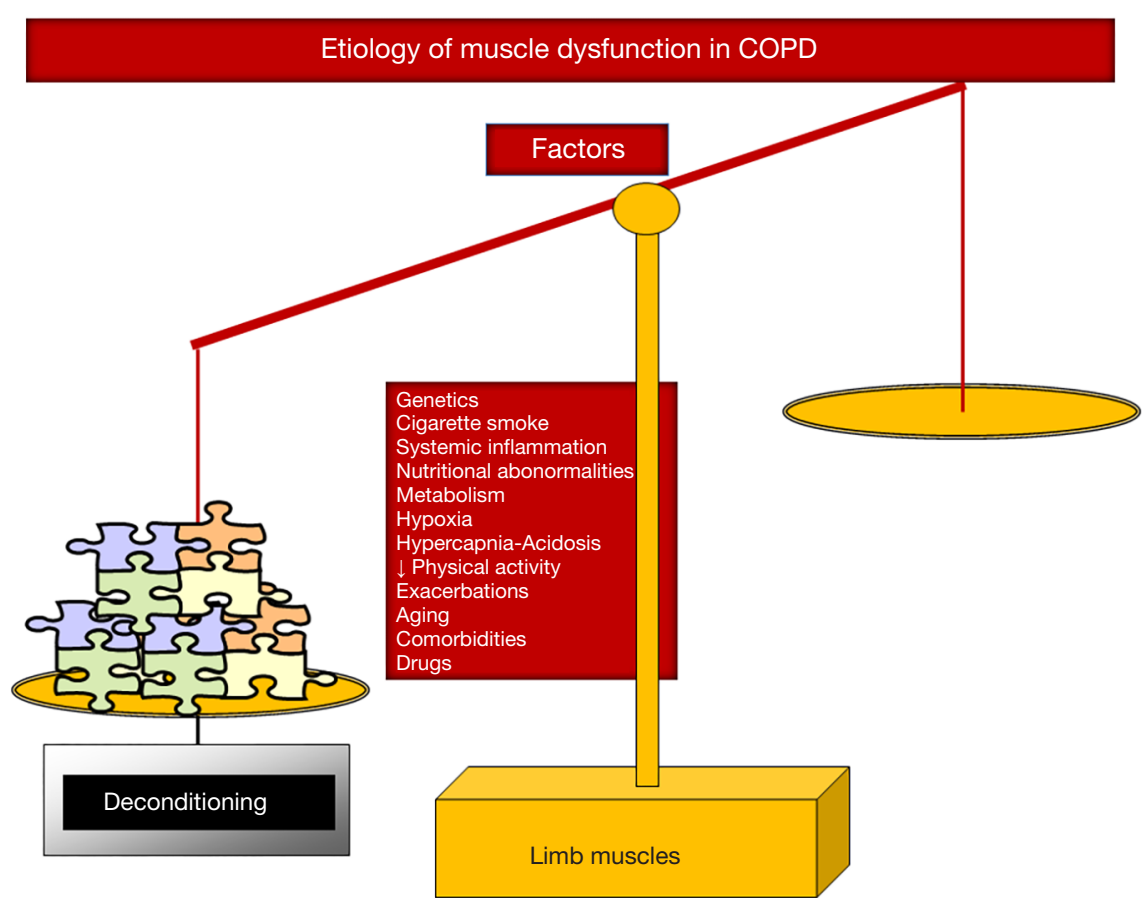

Figure 2 Several etiologic factors involved in the multifactorial etiology of muscle dysfunction exert deleterious effects on the function and mass (deconditioning) of lower limb muscles in patients with COPD. Hence, the balance is completely skewed towards the negative side.

and contacts $(41,42)$ that could eventually impair oxygen delivery to the myofibers (43-45) is another contributing biological mechanism. Other structural abnormalities such as muscle cell membrane and sarcomere damage may also negatively influence muscle function (36). Mitochondrial derangements of several types were also demonstrated to alter muscle function in COPD (46-48) (Figure 3).

Chronic hypoxia induced a reduction in muscle mass probably as a result of the interaction of several molecular mediators such as inflammation (49), hypoxia inducible factor-1 signaling pathway (50), oxidative stress $(51,52)$, and reduced oxidative enzyme capacity and capillary numbers $(37,53)$. Hypercapnia, which may worsen during exacerbations, may also play a role in COPD muscle dysfunction through acidosis as it enhances ubiquitinproteasome proteolytic system activity and/or through a reduction in protein anabolism (54) (Figure 3).

Oxidative stress, defined as the imbalance between oxidants and antioxidants, and as measured by several markers such as protein oxidation and nitration and lipid peroxidation has been consistently shown in blood and limb muscles of patients with severe COPD both at rest and after exercise (34,36,52,55-62). Importantly, oxidative stress markers were also shown to inversely correlate with several clinical and physiological parameters such as exercise capacity, body composition, and quadriceps strength of the patients $(34,36,57,58,62)$ (Figure 3). Although oxidative stress and inflammation have been previously associated, evidence shows that local inflammatory events do not seem to occur in muscles of COPD patients $(34,36,52,57,59,62,63)$, even in atrophying muscles or during exacerbations.

Cigarette smoking may also contribute to limb muscle dysfunction in COPD through several biological mechanisms such as decreased type I fiber sizes and proportions and reduced mitochondrial activity, while concomitantly causing an increase in oxidative stress levels in healthy smokers and experimental animal models of chronic exposure to cigarette smoke $(59,64,65)$ (Figure 2). Other relevant molecular and cellular events that have been shown to mediate muscle mass loss and dysfunction in COPD from different etiologic factors are increased proteolysis (34,36), apoptosis (63), epigenetic mechanisms (35,66-69), increased autophagy (36) and endoplasmic reticulum response (unpublished observations) (Figure 3).

\section{Diaphragm muscle dysfunction}

Given that ventilatory muscles are chronically exposed to 


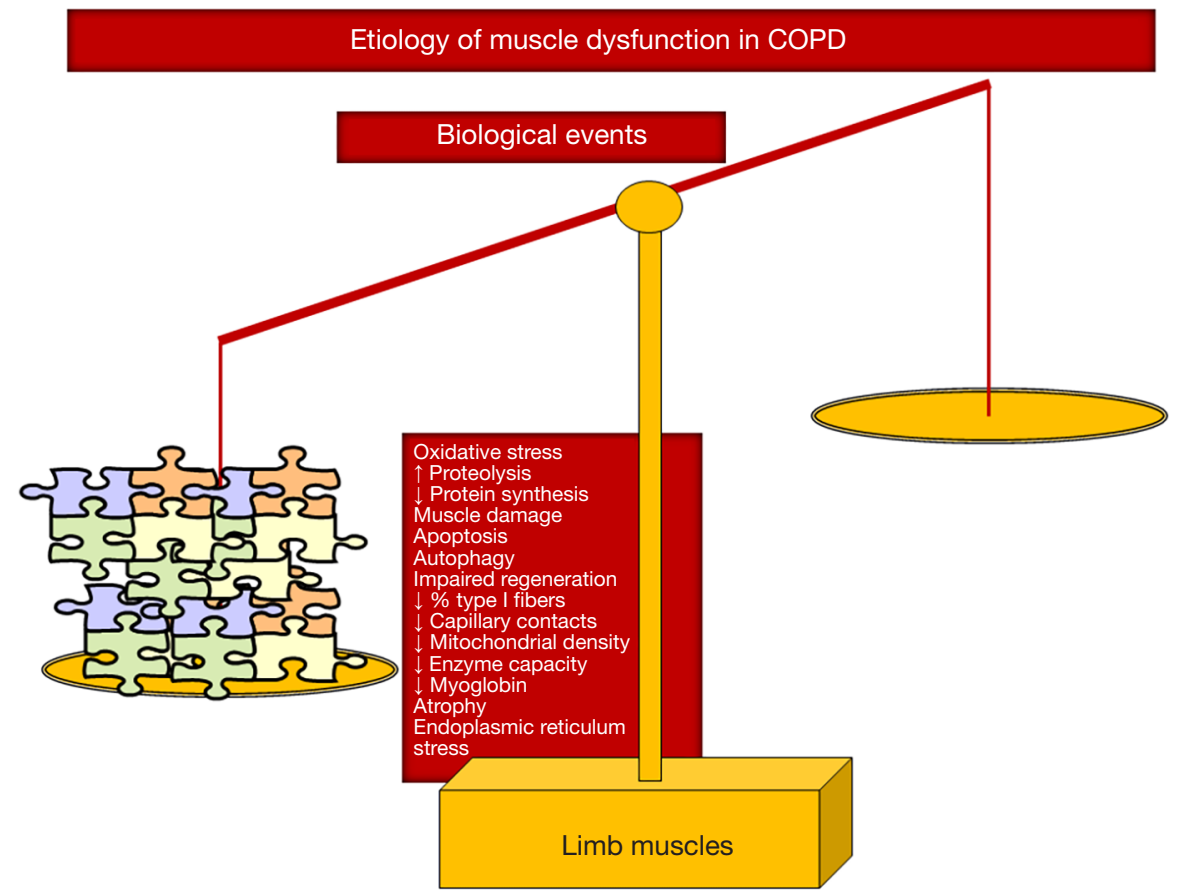

Figure 3 In lower limb muscles, several biological events that mediate the actions of the etiologic factors exert direct deleterious effects on muscle function, structure, and mass. Hence, the balance is completely skewed towards the negative side.

higher inspiratory loads and must remain active throughout the existence of the COPD patients, they are less severely affected than the lower limb muscles. In the last years, ventilatory muscles have been studied through the analyses of the costal diaphragm, with very restricted access, and only via thoracotomy performed for clinical reasons (mainly lung cancer and lung volume reduction surgeries).

In COPD patients, ventilatory mechanics is altered as a result of static pulmonary hyperinflation, which modifies thorax geometry and shortens the diaphragm length, and displace the muscle away from its optimal length to generate the required forces (16-19). Additionally, muscles need to overcome the increased work of breathing resulting from the greater elastic, resistive, and threshold inspiratory loads imposed by airflow limitation (16-19). These factors, which are inherent to the respiratory condition (ventilatory mechanics alterations), constitute the main contributors to respiratory muscle dysfunction in COPD (Figure 4). However, it has also been shown that in COPD patients, the respiratory muscles undergo a positive adaptation (training-like effect) that renders them, especially the diaphragm, more fatigue-resistant compared to diaphragm forces developed by healthy subjects when exposed to identical lung volumes (16-19) (Figure 4). Finally, similar etiologic factors involved in the dysfunction of the lower limb muscles may also affect, to different degrees, the respiratory muscles in COPD: cigarette smoke, hypoxia, hypercapnia and acidosis, metabolic derangements, malnutrition, genetics, systemic inflammation, aging, comorbidities, concomitant treatments, exacerbations, and reduced physical activity (5,16-19) (Figure 4). Nevertheless, in COPD respiratory muscle dysfunction, exacerbations, nutritional abnormalities, and aging are likely to play a key role above the other contributing factors (5,16-19).

As illustrated in Figure 5, several molecular and cellular events that take place in the lower limb muscles also seem to mediate the effects of the different etiologic factors that negatively influence phenotype and function in the respiratory muscles. Other specific cellular events mediate beneficial effects (adaptive biological mediators) on the diaphragm of COPD patient such as shorter sarcomere length, higher proportions of slow-twitch fibers and myoglobin content, increased capillary contacts per fiber, increased mitochondrial density, and enhanced aerobic enzyme capacity [for specific review see (16-19)] (Figure 5). On this basis, the adaptive mechanisms may offset to certain extent the adverse phenotypic features in the diaphragm of patients with COPD. In these patients, the net effect on the 


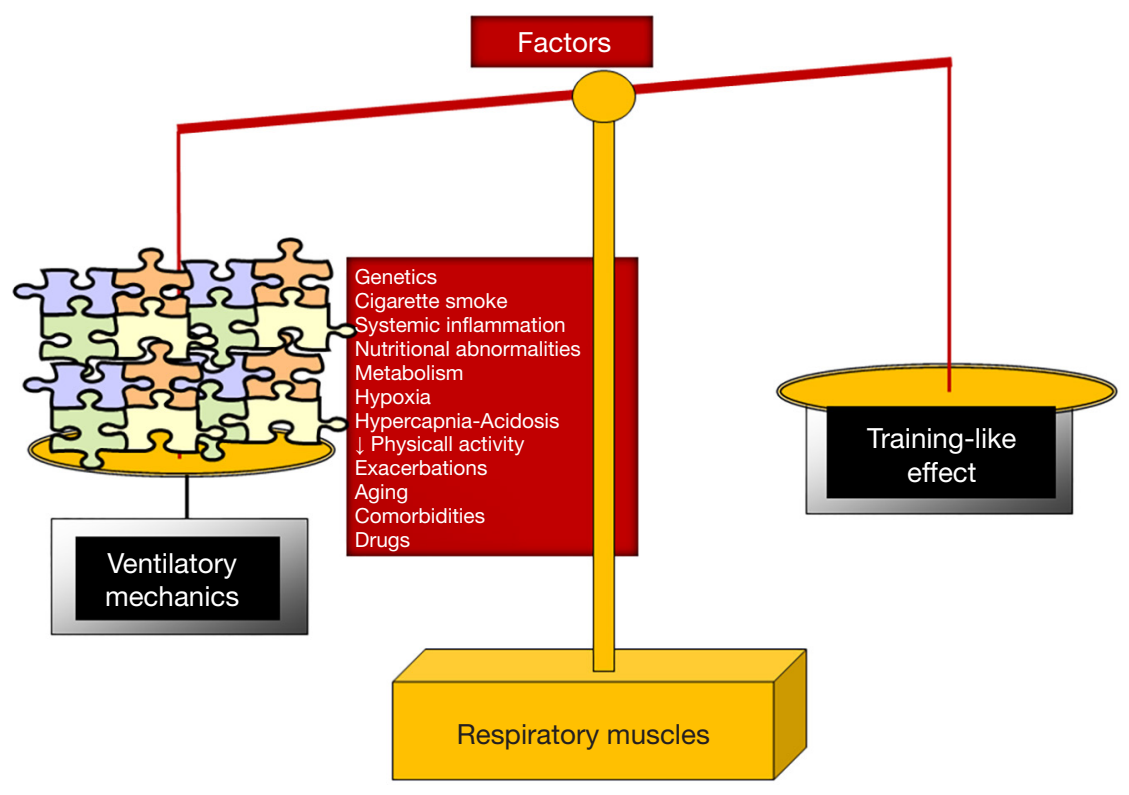

Figure 4 Schematic representation on how the different reported etiologic factors contribute to respiratory muscle dysfunction in COPD through the action of several biological mechanisms that modify muscle phenotype and function in the patients. Notice that in the COPD respiratory muscle dysfunction, as opposed to dysfunction of the lower limb muscles, several etiologic factors may exert beneficial effects (training-like effect) on muscle mass and performance through the action of different biological mediators (adaptive mechanisms) that lead to adaptation of the inspiratory muscles in COPD. These adaptive mechanisms partly counterbalance the deleterious effects of other factors and mechanisms of a rather systemic nature (depicted in the left-hand side of the figure).

ventilatory muscle function will depend on the balance between deleterious and adaptive biological mediators (Figure 5), which may also differ between stable and acute conditions within the same patient. Interestingly, in the external intercostal muscle of COPD patients, similar adaptive cellular events may also take place (16-19). In advanced COPD, however, biological mechanisms concomitantly affecting the lower limbs such as injury, oxidative stress, enhanced proteolysis and reduced anabolism, apoptosis, and epigenetic events will prevail over the adaptive mechanisms (Figure 5).

\section{Concluding remarks}

Skeletal muscle dysfunction is a major systemic manifestation in patients with respiratory conditions. In the last two decades, most of the research in this field has been devoted to the elucidation of the prevalence and etiology of muscle dysfunction in COPD. Muscle weakness and wasting predict morbidity and mortality in patients with COPD. However, the mechanisms potentially linking muscle dysfunction and the primary organ disease remain to be fully elucidated. Current avenues of research in this field focus on the identification of biological mechanisms that may help design novel therapeutic strategies to better treat muscle dysfunction in COPD regardless of the lung disease. More research is needed to identify other mechanisms that could be targeted with specific therapies. Clinical trials in which currently available therapies were tested should be conducted in the near future, especially those emerging from studies in animal models, in which muscle function and mass loss were shown to be recovered. Moreover, interest on the elucidation of the pathophysiology of muscle dysfunction in the critically ill patient is also growing. Evidence emerging from the field of COPD muscle dysfunction should be used as a model to enhancing current knowledge on the specific role of muscle weakness and dysfunction in patients bearing other chronic respiratory disorders, in which muscle dysfunction is prevalent, as well as in critical illness. Importantly, the specific contribution to muscle dysfunction of therapies commonly prescribed in patients with chronic respiratory 


\section{Etiology of muscle dysfunction in COPD}

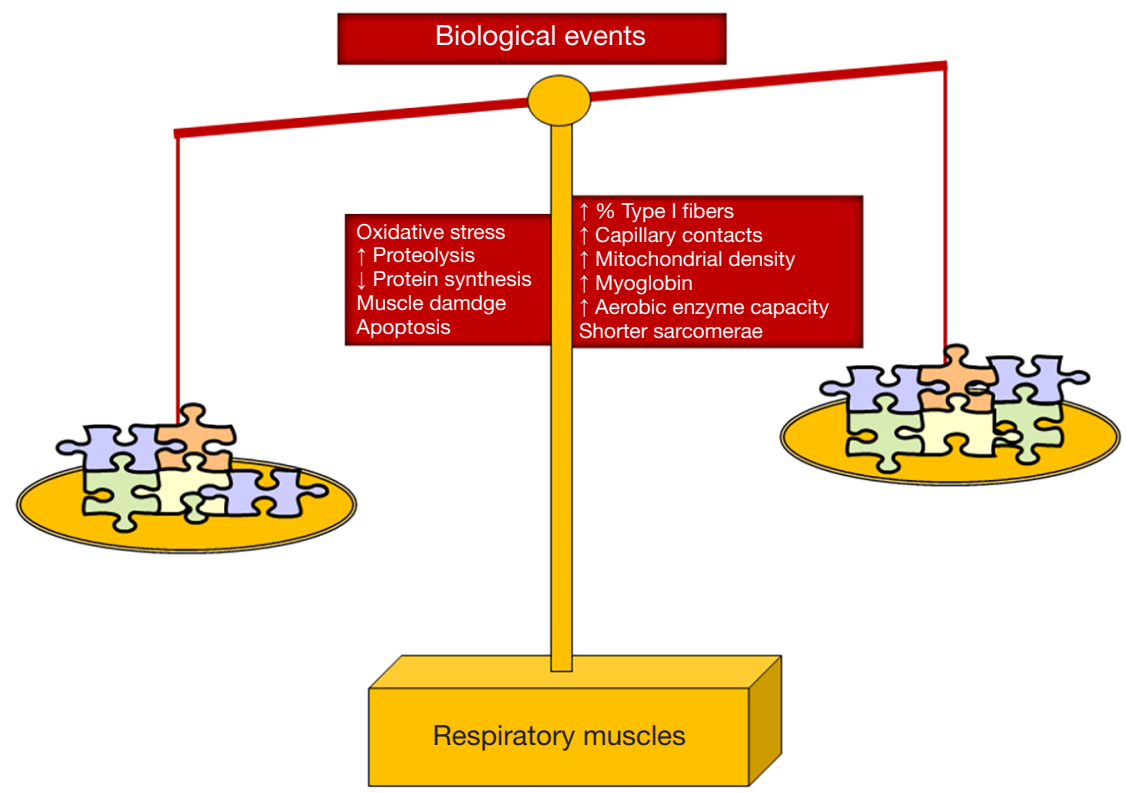

Figure 5 In the respiratory muscles, several cellular and molecular mechanisms exert beneficial effects (adaptive mechanisms, right-hand side tray), which partly counterbalance the deleterious actions of other biological events (left-hand side tray).

disorders and critical illness such as systemic corticosteroids and immunosuppressant drugs should also be the focus of future research in those patients. Given its prognostic value, the assessment of skeletal muscle dysfunction should be included in the routine evaluation of patients with chronic respiratory disorders and in critical care settings.

\section{Acknowledgements}

Part of the research described in this review has been funded by CIBERES, FIS 14/00713 (FEDER), unrestricted grant from Menarini SA 2014, SEPAR 2016, FUCAP 2016 (E Barreiro) and NHLBI of the National Institutes of Health under the award number K01-HL130704-01, and by the Collins Family Foundation Endowment (A Jaitovich).

\section{Footnote}

Conflicts of Interest: The authors have no conflicts of interest to declare.

\section{References}

1. Miravitlles M. What was the impact of the Spanish COPD guidelines (GesEPOC) and how can they be improved? Arch Bronconeumol 2016;52:1-2.

2. Miravitlles M, Soler-Cataluna JJ. GOLD in 2017: A View From the Spanish COPD Guidelines (GesCOPD). Arch Bronconeumol 2017;53:89-90.

3. Miravitlles M, Soler-Cataluna JJ, Calle M, et al. Spanish Guidelines for Management of Chronic Obstructive Pulmonary Disease (GesEPOC) 2017. Pharmacological Treatment of Stable Phase. Arch Bronconeumol 2017;53:324-35.

4. Vogelmeier CF, Criner GJ, Martinez FJ, et al. Global Strategy for the Diagnosis, Management, and Prevention of Chronic Obstructive Lung Disease 2017 Report: GOLD Executive Summary. Arch Bronconeumol 2017;53:128-49.

5. Maltais F, Decramer M, Casaburi R, et al. An official American Thoracic Society/European Respiratory Society statement: update on limb muscle dysfunction in chronic obstructive pulmonary disease. Am J Respir Crit Care Med 2014;189:e15-62.

6. Gea J, Martinez-Llorens J, Barreiro E. Nutritional abnormalities in chronic obstructive pulmonary disease. Med Clin (Barc) 2014;143:78-84.

7. Marquis K, Debigare R, Lacasse Y, et al. Midthigh 
muscle cross-sectional area is a better predictor of mortality than body mass index in patients with chronic obstructive pulmonary disease. Am J Respir Crit Care Med 2002;166:809-13.

8. Shrikrishna D, Patel M, Tanner RJ, et al. Quadriceps wasting and physical inactivity in patients with COPD. Eur Respir J 2012;40:1115-22.

9. Swallow EB, Reyes D, Hopkinson NS, et al. Quadriceps strength predicts mortality in patients with moderate to severe chronic obstructive pulmonary disease. Thorax 2007;62:115-20.

10. Gayan-Ramirez G, Decramer M. Mechanisms of striated muscle dysfunction during acute exacerbations of COPD. J Appl Physiol 2013;114:1291-9.

11. Bachasson D, Wuyam B, Pepin JL, et al. Quadriceps and respiratory muscle fatigue following high-intensity cycling in COPD patients. PLoS One 2013;8:e83432.

12. Burtin C, Saey D, Saglam M, et al. Effectiveness of exercise training in patients with COPD: the role of muscle fatigue. Eur Respir J 2012;40:338-44.

13. Coronell C, Orozco-Levi M, Mendez R, et al. Relevance of assessing quadriceps endurance in patients with COPD. Eur Respir J 2004;24:129-36.

14. Mador MJ, Bozkanat E, Kufel TJ. Quadriceps fatigue after cycle exercise in patients with COPD compared with healthy control subjects. Chest 2003;123:1104-11.

15. Marquis N, Debigare R, Bouyer L, et al. Physiology of walking in patients with moderate to severe chronic obstructive pulmonary disease. Med Sci Sports Exerc 2009;41:1540-8.

16. Barreiro E, Bustamante V, Cejudo P, et al. Guidelines for the evaluation and treatment of muscle dysfunction in patients with chronic obstructive pulmonary disease. Arch Bronconeumol 2015;51:384-95.

17. Barreiro E, Gea J. Respiratory and Limb Muscle Dysfunction in COPD. COPD 2015;12:413-26.

18. Barreiro E, Gea J. Molecular and biological pathways of skeletal muscle dysfunction in chronic obstructive pulmonary disease. Chron Respir Dis 2016;13:297-311.

19. Gea J, Agusti A, Roca J. Pathophysiology of muscle dysfunction in COPD. J Appl Physiol 2013;114:1222-34.

20. Gosselink R, Troosters T, Decramer M. Distribution of muscle weakness in patients with stable chronic obstructive pulmonary disease. J Cardiopulm Rehabil 2000;20:353-60.

21. Gosselink R, De VJ, van den Heuvel SP, et al. Impact of inspiratory muscle training in patients with COPD: what is the evidence? Eur Respir J 2011;37:416-25.

22. Simpson K, Killian K, McCartney N, et al. Randomised controlled trial of weightlifting exercise in patients with chronic airflow limitation. Thorax 1992;47:70-5.

23. Decramer M, Gosselink R, Troosters T, et al. Muscle weakness is related to utilization of health care resources in COPD patients. Eur Respir J 1997;10:417-23.

24. Seymour JM, Spruit MA, Hopkinson NS, et al. The prevalence of quadriceps weakness in COPD and the relationship with disease severity. Eur Respir J 2010;36:81-8.

25. Levine S, Bashir MH, Clanton TL, et al. COPD elicits remodeling of the diaphragm and vastus lateralis muscles in humans. J Appl Physiol 2013;114:1235-45.

26. Similowski T, Yan S, Gauthier AP, et al. Contractile properties of the human diaphragm during chronic hyperinflation. N Engl J Med 1991;325:917-23.

27. Ramírez-Sarmiento A, Orozco-Levi M, Barreiro E, et al. Expiratory muscle endurance in chronic obstructive pulmonary disease. Thorax 2002;57:132-6.

28. Ramirez-Sarmiento A, Orozco-Levi M, Guell R, et al. Inspiratory muscle training in patients with chronic obstructive pulmonary disease: structural adaptation and physiologic outcomes. Am J Respir Crit Care Med 2002;166:1491-7.

29. Vilaró J, Ramirez-Sarmiento A, Martinez-Llorens $\mathrm{JM}$, et al. Global muscle dysfunction as a risk factor of readmission to hospital due to COPD exacerbations. Respir Med 2010;104:1896-902.

30. Crul T, Testelmans D, Spruit MA, et al. Gene expression profiling in vastus lateralis muscle during an acute exacerbation of COPD. Cell Physiol Biochem 2010;25:491-500.

31. Pitta F, Troosters T, Probst VS, et al. Physical activity and hospitalization for exacerbation of COPD. Chest 2006;129:536-44.

32. Spruit MA, Gosselink R, Troosters T, et al. Muscle force during an acute exacerbation in hospitalised patients with COPD and its relationship with CXCL8 and IGF-I. Thorax 2003;58:752-6.

33. Decramer M, de Bock V, Dom R. Functional and histologic picture of steroid-induced myopathy in chronic obstructive pulmonary disease. Am J Respir Crit Care Med 1996;153:1958-64.

34. Fermoselle C, Rabinovich R, Ausin P, et al. Does oxidative stress modulate limb muscle atrophy in severe COPD patients? Eur Respir J 2012;40:851-62.

35. Puig-Vilanova E, Martinez-Llorens J, Ausin P, et al. Quadriceps muscle weakness and atrophy are associated with a differential epigenetic profile in advanced COPD. 
Clin Sci (Lond) 2015;128:905-21.

36. Puig-Vilanova E, Rodriguez DA, Lloreta J, et al. Oxidative stress, redox signaling pathways, and autophagy in cachectic muscles of male patients with advanced COPD and lung cancer. Free Radic Biol Med 2015;79:91-108.

37. Torres SH, Montes de OM, Loeb E, et al. Gender and skeletal muscle characteristics in subjects with chronic obstructive pulmonary disease. Respir Med 2011;105:88-94.

38. Lexell J, Downham D. What is the effect of ageing on type 2 muscle fibres? J Neurol Sci 1992;107:250-1.

39. Kelsen SG, Ference M, Kapoor S. Effects of prolonged undernutrition on structure and function of the diaphragm. J Appl Physiol (1985) 1985;58:1354-9.

40. Dekhuijzen PN, Decramer M. Steroid-induced myopathy and its significance to respiratory disease: a known disease rediscovered. Eur Respir J 1992;5:997-1003.

41. Jobin J, Maltais F, Doyon JF, et al. Chronic obstructive pulmonary disease: capillarity and fiber-type characteristics of skeletal muscle. J Cardiopulm Rehabil 1998;18:432-7.

42. Whittom F, Jobin J, Simard PM, et al. Histochemical and morphological characteristics of the vastus lateralis muscle in patients with chronic obstructive pulmonary disease. Med Sci Sports Exerc 1998;30:1467-74.

43. Maltais F, LeBlanc P, Whittom F, et al. Oxidative enzyme activities of the vastus lateralis muscle and the functional status in patients with COPD. Thorax 2000;5 5:848-53.

44. Saey D, Michaud A, Couillard A, et al. Contractile fatigue, muscle morphometry, and blood lactate in chronic obstructive pulmonary disease. Am J Respir Crit Care Med 2005;171:1109-15.

45. Saey D, Lemire BB, Gagnon P, et al. Quadriceps metabolism during constant workrate cycling exercise in chronic obstructive pulmonary disease. J Appl Physiol 2011;110:116-24.

46. Naimi AI, Bourbeau J, Perrault H, et al. Altered mitochondrial regulation in quadriceps muscles of patients with COPD. Clin Physiol Funct Imaging 2011;31:124-31.

47. Puente-Maestu L, Perez-Parra J, Godoy R, et al. Abnormal transition pore kinetics and cytochrome $\mathrm{C}$ release in muscle mitochondria of patients with chronic obstructive pulmonary disease. Am J Respir Cell Mol Biol 2009;40:746-50.

48. Puente-Maestu L, Lazaro A, Tejedor A, et al. Effects of exercise on mitochondrial DNA content in skeletal muscle of patients with COPD. Thorax 2011;66:121-7.

49. Takabatake N, Nakamura H, Abe S, et al. The relationship between chronic hypoxemia and activation of the tumor necrosis factor-alpha system in patients with chronic obstructive pulmonary disease. Am J Respir Crit Care Med 2000;161:1179-84.

50. Caron MA, Theriault ME, Pare ME, et al. Hypoxia alters contractile protein homeostasis in L6 myotubes. FEBS Lett 2009;583:1528-34.

51. Chandel NS, McClintock DS, Feliciano CE, et al. Reactive oxygen species generated at mitochondrial complex III stabilize hypoxia-inducible factor-1alpha during hypoxia: a mechanism of O2 sensing. J Biol Chem 2000;275:25130-8.

52. Koechlin C, Maltais F, Saey D, et al. Hypoxaemia enhances peripheral muscle oxidative stress in chronic obstructive pulmonary disease. Thorax 2005;60:834-41.

53. de Theije C, Costes F, Langen RC, et al. Hypoxia and muscle maintenance regulation: implications for chronic respiratory disease. Curr Opin Clin Nutr Metab Care 2011;14:548-53.

54. Jaitovich A, Angulo M, Lecuona E, et al. High CO2 levels cause skeletal muscle atrophy via AMP-activated kinase (AMPK), FoxO3a protein, and muscle-specific Ring finger protein 1 (MuRF1). J Biol Chem 2015;290:9183-94.

55. Barreiro E, de la Puente B, Minguella J, et al. Oxidative stress and respiratory muscle dysfunction in severe chronic obstructive pulmonary disease. Am J Respir Crit Care Med 2005;171:1116-24.

56. Barreiro E, Galdiz JB, Marinan M, et al. Respiratory loading intensity and diaphragm oxidative stress: $\mathrm{N}$-acetylcysteine effects. J Appl Physiol 2006;100:555-63.

57. Barreiro E, Schols AM, Polkey MI, et al. Cytokine profile in quadriceps muscles of patients with severe COPD. Thorax 2008;63:100-7.

58. Barreiro E, Rabinovich R, Marin-Corral J, et al. Chronic endurance exercise induces quadriceps nitrosative stress in patients with severe COPD. Thorax 2009;64:13-9.

59. Barreiro E, Peinado VI, Galdiz JB, et al. Cigarette smokeinduced oxidative stress: A role in chronic obstructive pulmonary disease skeletal muscle dysfunction. Am J Respir Crit Care Med 2010;182:477-88.

60. Bustamante V, Casanova J, López de Santamaría E, et al. Redox balance following magnetic stimulation training in the quadriceps of patients with severe COPD. Free Radic Res 2008;42:939-48.

61. Koechlin C, Couillard A, Simar D, et al. Does oxidative stress alter quadriceps endurance in chronic obstructive pulmonary disease? Am J Respir Crit Care Med 2004;169:1022-7.

62. Rodriguez DA, Kalko S, Puig-Vilanova E, et al. Muscle and blood redox status after exercise training in severe COPD patients. Free Radic Biol Med 2012;52:88-94. 
63. Barreiro E, Ferrer D, Sanchez F, et al. Inflammatory cells and apoptosis in respiratory and limb muscles of patients with COPD. J Appl Physiol 2011;111:808-17.

64. Barreiro E, del Puerto-Nevado L, Puig-Vilanova E, et al. Cigarette smoke-induced oxidative stress in skeletal muscles of mice. Respir Physiol Neurobiol 2012;182:9-17.

65. Montes de Oca M, Loeb E, Torres SH, et al. Peripheral muscle alterations in non-COPD smokers. Chest 2008;133:13-8.

66. Barreiro E, Sznajder JI. Epigenetic regulation of muscle phenotype and adaptation: a potential role in COPD muscle dysfunction. J Appl Physiol 2013;114:1263-72.

Cite this article as: Barreiro E, Jaitovich A. Muscle atrophy in chronic obstructive pulmonary disease: molecular basis and potential therapeutic targets. J Thorac Dis 2018;10(Suppl 12):S1415-S1424. doi: 10.21037/jtd.2018.04.168
67. Barreiro E, Gea J. Epigenetics and muscle dysfunction in chronic obstructive pulmonary disease. Transl Res 2015;165:61-73.

68. Puig-Vilanova E, Ausin P, Martinez-Llorens J, et al. Do epigenetic events take place in the vastus lateralis of patients with mild chronic obstructive pulmonary disease? PLoS One 2014;9:e102296.

69. Puig-Vilanova E, Aguilo R, Rodriguez-Fuster A, et al. Epigenetic mechanisms in respiratory muscle dysfunction of patients with chronic obstructive pulmonary disease. PLoS One 2014;9:e111514. 